\title{
Increasing Scaffold Branch Angle of Atemoya by Manipulation of the Primary Bud Complex
}

\author{
Thomas E. Marler ${ }^{1}$ \\ Fairchild Tropical Garden, 11935 Old Cutler Road, Miami, FL 33156 \\ Jonathan H. Crane \\ Tropical Research and Education Center, University of Florida, Institute of \\ Food and Agricultural Sciences, Homestead, FL 33031
}

Additional index words. annona, Annona squamosa $\times$ A. cherimola, supernumerary buds, tree training, tropical fruit

\begin{abstract}
Lateral branches arising from the primary bud complex on limbs of containerized 'Gefner' atemoya (Annona squamosa L. $\times$ A. cherimola Mill.) plants were removed to determine the influence of branch regrowth on the crotch angle. Pruning the lateral branches to a stub $(\mathrm{cl} \mathrm{cm})$ was more effective in inducing regrowth and increasing branch angle of the regrowth than stripping lateral branches by hand. Following lateral branch removal, regrowth did not develop from every node along a stem axis. In a second study, the angle of branch regrowth from tagged nodes following pruning of lateral branches was determined. The mean crotch angle of the primary lateral branches was $58^{\circ}$. Regrowth from the second and third supernumerary buds within each node produced branches with an average crotch angle of $72^{\circ}$ and $88^{\circ}$, respectively. The largest increase in attachment angle following pruning was obtained at nodes with narrow primary lateral branches and at nodes located closest to the base of a major axis. The increase in branch crotch angle was not correlated with the size of the preceding lateral branch at a node. These results indicate that pruning off lateral branches with narrow crotch angles may be performed during training atemoya plants to produce scaffold limbs from supernumerary buds within the same nodes with desirably wide crotch angles.
\end{abstract}

The importance of atemoya as a commercial crop in Florida (Crane, 1989) and the tropics is increasing. Narrow crotch angles in atemoya can lead to breaking limbs in untrained trees under high-wind or ice conditions when overhead irrigation is used for cold protection, or heavy fruit load. Therefore, some training of the canopy is necessary when trees are young to induce wide crotch angles (Campbell and Phillips, 1980; Sanewski, 1988). This practice is common for many deciduous fruit trees (Westwood, 1978).

Atemoya and other members of the Annonaceae family exhibit distichous phyllotaxis with a primary bud complex consisting of several meristems initiated separately in a single leaf axis (Halle et al., 1978). In atemoya, up to six meristems are arranged in a vertical series at each node (L.E. Willis, unpublished). Lateral branches are also arranged distichously, leading to required, repeated pruning of scaffold branches to develop an atemoya tree into a modified central leader or open center shape (unpublished data)

$\overline{\text { Received for }}$ publication 25 June 1993. Accepted for publication 7 Jan. 1994, The cost of publishing this-paper was defrayed in part by the payment of page charges. Under postal regulations, this paper therefore must be hereby marked advertisement solely to indicate this fact.

${ }^{1}$ Current address: College of Agriculture and Life Sciences, Univ. of Guam, UOG Station, Mangilao, Guam 96923.
Amling (1976) described a training system in which the selection of the proper lateral shoot from the primary bud complex of pecan [Carya illinoinensis (Wangenh.) C. Koch] was used to create proper scaffold branch angles. Our field observations indicated that a similar technique could be used to train atemoya trees. Our objectives were to determine the influence of repeated removal of lateral atemoya branches on the angle of subsequent branches developing from supernumerary buds and to determine the influence of pruning or hand-stripping to remove the lateral, the position of a node on a main axis, and the size of removed lateral branches on the crotch angle of the subsequent lateral branch within a node.

\section{Materials and Methods}

Preliminary study. Five container-grown atemoya trees were used in a preliminary study to determine an effective method for removing lateral branches to force initiation of subsequent lateral branches. The number and crotch angle of all lateral branches on each major limb was measured on 7 Mar. 1990. Then lateral branches were removed from two trees by pruning them to a stub $(<1 \mathrm{~cm})$ or by stripping them off by hand from three additional trees. This procedure was repeated on 23 Apr. and 15 June. The total number of lateral branches that were measured ranged from 209 to 329, depending on measurement date.
Main study. Five atemoya trees with a mean height of $140 \mathrm{~cm}$ were transferred to a glasshouse in Mar. 1990. The plants were watered daily and fertilized with a granular material (12N-2.6P-6.6K Plus micronutrients) at $30 \mathrm{~g} /$ pot on 25 Apr., 10-June, 22 Aug., and 9 Nov. 1990; The length, base diameter, and crotch angle of lateral branches were measured on 25 Apr. The nodes where measurements were made were tagged and numbered, and their distance from the base of each main axis was measured. All lateral shoots were removed by pruning to a stub as previously described. Lateral shoots were allowed to regrow from remaining supernumerary meristems, and measurement and pruning procedures were repeated on 11 June, 29 July, 14 Sept., and 21 Nov. 1990. The number of main axes ranged from five to eight per tree, and the number of tagged nodes ranged from two to six per axis. A total of 95 nodes were monitored through growth of two lateral shoots, and 49 nodes were monitored through growth of three lateral shoots.

We analyzed the lateral branch angle data by analysis of variance as a factorial in a randomized complete-block design with tree defined as the block. Treatments were node position on a major axis and lateral branch count at each node.

\section{Results and Discussion}

Preliminary study. Mean lateral branch angle increased from $53^{\circ}$ on 7 Mar. to $60^{\circ}$ or $59^{\circ}$ on 23 Apr. or 15 June, respectively, on major limbs of trees with laterals that had been pruned to a stub. Alternatively, hand stripping laterals had no influence on subsequent lateral branch angle. Moreover, trees that were pruned had an average of 15 lateral shoots on each major limb on 15 June, whereas trees with laterals stripped by hand had an average of nine. This reduction in initiation of regrowth associated with stripping the lateral branches by hand may have occurred due to damage to the remaining meristems within each treated node. The results from this preliminary study indicated that pruning was superior to hand stripping for forcing regrowth and increasing the mean crotch angle of that regrowth. We also observed that the measurements on 23 Apr. and 15 June included numerous nodes with primary lateral branches, rather than only secondary and tertiary lateral branches. A second study was undertaken to determine more accurately the angle of lateral branches arising from supernumerary buds following pruning of previous lateral branches at tagged nodes. The influence of node location on a major axis on lateral branch crotch angle also was determined.

Main study. Both treatments influenced the crotch angle of branches at tagged nodes $(P$ $0.01)$. No interactions occurred among the treatments, and there was no difference in crotch angle of lateral branches among the trees.

Crotch angle of the primary lateral branches was $58^{\circ} \pm 1^{\circ}$. Following pruning and regrowth, crotch angle was $72^{\circ} \pm 1^{\circ}$ or $88^{\circ} \pm 2^{\circ}$ for the 
secondary or tertiary lateral branches, respectively. Of the secondary lateral branches, $>90 \%$ developed immediately after pruning the primary lateral branches. Another 8\% developed after the 11 June and 9 Aug. pruning dates. Only $1 \%$ of the nodes exhibited no regrowth after removal of the primary lateral branch. However, $39 \%$ of the tagged nodes where secondary lateral branches were removed never developed tertiary lateral branches before the end of the study. Many lateral branches at nodes that were not tagged or measured exhibited growth initiation on the major axes containing the tagged nodes that did not develop tertiary regrowth. These observations indicate that immediate regrowth at some nodes along an axis inhibited regrowth at other nodes along the same axis.

The relationship between the position of a node on a major axis and the associated increase in crotch angle of the forced regrowth from supernumerary meristems was determined by regression analysis, using distance from the base of an axis as the independent variable and angle of the primary or tertiary lateral branch as the dependent variable. Nodal distance from the base of an axis was inversely related (slope $=-0.2, P \leq 0.01$ ) to tertiary branch angle. The calculated angles of tertiaty branches located 6 or $91 \mathrm{~cm}$ from the base of an axis (the range of our data) were $97^{\circ}$ or $80^{\circ}$, respectively. This influence of location along a main axis was due to the manipulation procedure because the angle of the primary lateral branches was not dependent on nodal location.

We assume that one reason for the increase in crotch angle for a branch arising from a secondary or tertiary meristem was the obstruction by the base of the lateral branch arising from the previous meristem because each successive supernumerary meristem of atemoya subtends the previous one within a node. As a result, the relationship between the size (length or basal diameter) of the pruned lateral branches within each treated node and the associated increase in crotch angle of subsequent branches was determined by regression analysis. The increase in crotch angle from one branch to the next at a node did not depend on the length or diameter of the previous lateral branch. This result was unexpected because there was a wide range in size of

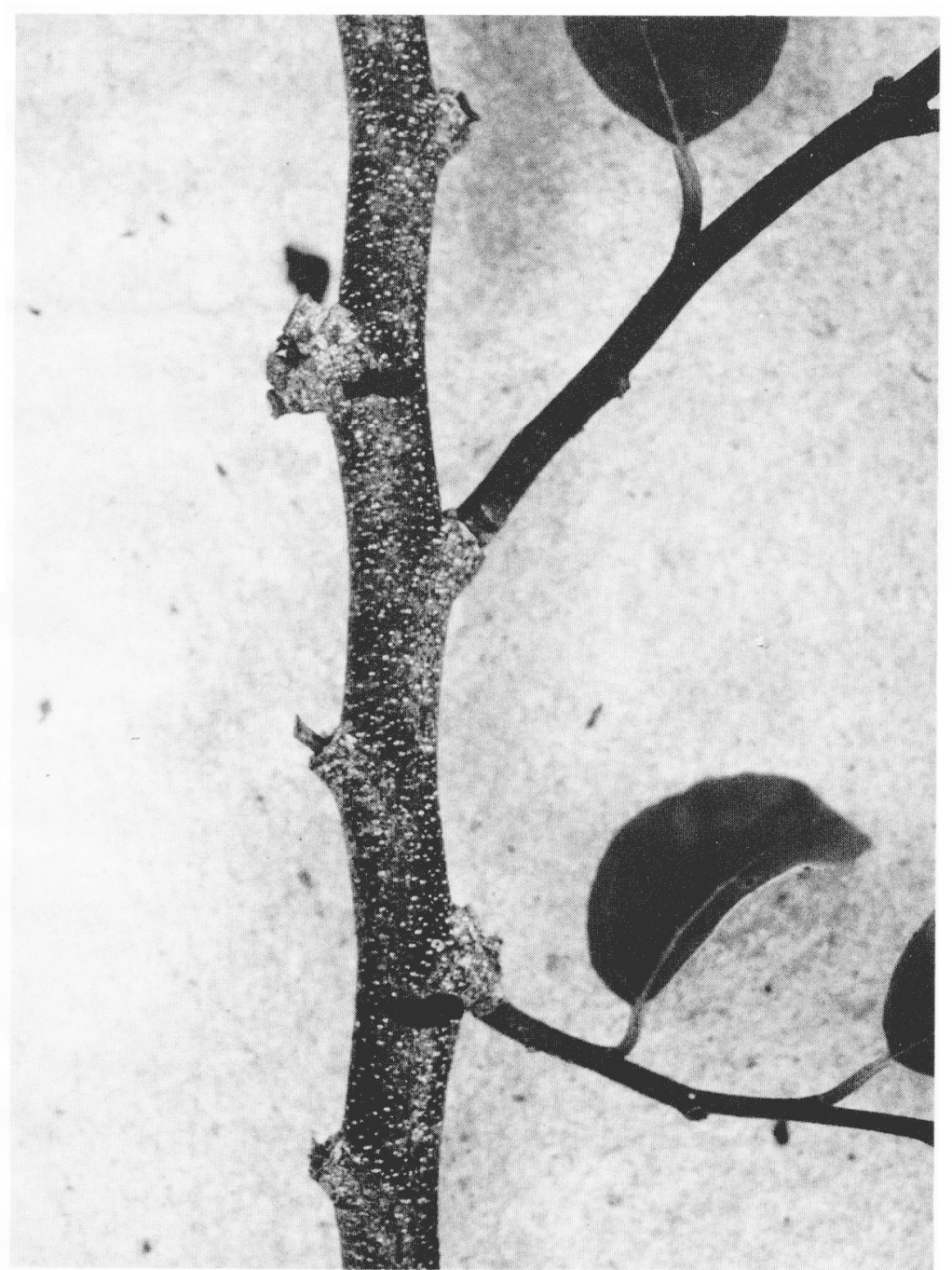

Fig. 1. Phenotype of a 'Gefner' atemoya shoot with an nonmanipulated node showing (top) an undesirably narrow angle of the lateral branch from a primary bud and (bottom) an undesirably wide angle of the lateral branch from a supernumerary bud after three successive pruning procedures bottom. Note the buildup of tissue from the base of previously pruned lateral branches immediately above the remaining branch at the manipulated node. removed lateral shoots (1-32 $\mathrm{cm}$ in length and 0.1-0.7 $\mathrm{cm}$ in diameter).

The increase in crotch angle due to removal of lateral shoots was undesirably large in some cases, indicating the effectiveness of this procedure (Fig. 1). The crotch angle after regrowth of three laterals was $\leq 115^{\circ}$ at one tagged node, and the increase in crotch angle from one to the subsequent lateral was $\leq 50^{\circ}$. However, the mean increase in crotch angle from the branch arising from the primary bud to that of the branch arising from the tertiary bud (two successive pruning procedures) was $\approx 30^{\circ}$. These data indicate that each time a lateral atemoya branch is removed by pruning, a mean $15^{\circ}$ increase in crotch angle could be expected for the subsequent lateral branch arising from a remaining supernumerary bud.

A limb attachment of at least $45^{\circ}$ is desirable for more common training systems used with fruit trees, such as open center, central leader, and modified central leader (Micke et al., 199 1). However, limb attachments angels $>70^{\circ}$ are desirable for the single-leader spindle system. Little research has been conducted to determine the optimum training system for atemoya; however, observations indicate that training systems leading to an open center are desirable (Campbell and Phillips, 1980; Sanewski, 1988). Our data indicate that many lateral branches of atemoya have an attachment angle that will lead to a sufficiently strong tree canopy. Narrow crotches are prevalent enough in nonpruned atemoya trees, however, to lead to structurally unsound canopies and severe limb breakage (George and Nissen, 1986).

Regression analysis was used to examine more clearly the relationship between crotch angle of the primary lateral branch and the increase in crotch angle from the primary to secondary lateral branches. A negative slope $(P \leq 0.01)$ indicated that removing narrow primary lateral branches led to the greatest increase in crotch angle of the secondary lateral branches. Removing primary lateral branches with attachment angles of $31^{\circ}$ or $80^{\circ}$ (the range of our data) led to estimated increases in limb attachment angle of $28^{\circ}$ or $11^{\circ}$, respectively. Therefore, this procedure has the most desirable influence on those lateral branches with the smallest attachment angles.

Casurd field observations indicated that a heading-back pruning cut on large atemoya limbs commonly induces growth of numerous supernumerary buds simultaneously within several nodes subtending the pruning cut. In these cases, the choice of the lateral branch with the most desirable crotch angle is possible with only one selective pruning, leaving the most desirable lateral branch.

Our results demonstrate that the numerous meristems within the primary bud complex at each node of atemoya shoots allow removal of the primary lateral branch to obtain regrowth at the same node. A mean $15^{\circ}$ increase in crotch angle may be expected to accompany the subsequent regrowth from anode, following pruning the previous lateral branch to a stub. The largest increase in attachment angle may be obtained from pruning off primary 
branches with narrow attachment angles. The removal procedure may be continued with the secondary lateral branch to obtain a further increase in crotch angle for the tertiary lateral branch. There is no advantage in waiting for the primary lateral branch to gain size before removal because the increase in crotch angle from one lateral branch to the next is independent of the size of the removed branch. The increase in limb attachment angle obtained from this procedure is less at nodes closer to the apex and greater at nodes closer to the base of a major axis. In cases where the crotch angle of the primary lateral branch is less than desired during training of young atemoya trees, this procedure may be used to obtain scaffold limbs with wider crotch angles, which are less susceptible to limb breakage.

\section{Literature Cited}

Amling, H.J. 1976. Training young pecan trees, Highlights of agricultural research. vol. 23, no, 1. Agr. Expt. Sta. Auburn Univ., Auburn, Ala.

Campbell, C.W. and R.L. Phillips. 1980. The atemoya. Florida Coop. Ext. Serv. Fruit Crops Fact Sheet FC-64.

Crane, J.H. 1989. Acreage and plant densities of commercial carambola, mamey sapote, lychee, longan, sugar apple, atemoya, and passion fruit plantings in south Florida. Proc. Fla. State Hort, Soc. 102:239-242.
George, A.P. and R.J. Nissen. 1986. Effect of pruning and defoliation on precocity of bearing of custard apple (Annona atemoya Hort.) var. African Pride. Acts Hort. 175:237-241.

Halle, F., R.A.A. Oldeman, and P.B. Tomlinson. 1978, Tropical trees and forests-An architectural analysis. Springer-Verlag, New York.

Micke, W., A. A. Hewitt, J.K. Clark, and M, Gerdts, 1991. Pruning fruit and nut trees. Univ. of California Div. Agr. and Natural Resources, Lflt. no. 21171.

Sanewski, G.M, 1988. Growing custard apples. Queensland Dept. Primary Industries, Information Series Q187014.

Westwood, M.N. 1978, Temperate zone pomology. W.H. Freeman, New York. 